\title{
PAULO FREIRE E O PENSAMENTO EDUCACIONAL PROGRESSISTA BRASILEIRO: ataques do Escola sem Partido
}

\author{
Isabela Maria Oliveira Catrinck \\ Maria Clara Maciel de Araíjo Ribeiro
}

\section{Resumo}

Objetiva-se evidenciar os ataques feitos pelo Movimento Escola sem Partido (MESP) aos princípios democráticos e autônomos do Pensamento Educacional Progressista Brasileiro (PEPB) através das ofensivas ao pensamento de Paulo Freire. Para tanto, através de uma pesquisa qualitativa, de cunho bibliográfico, destaca-se nomes expressivos no cenário educacional brasileiro: Anísio Teixeira, Paulo Freire e Dermeval Saviani, destacando Freire, bem como os desafios enfrentados por eles na defesa da educação democrática. Aborda-se, ainda, a construção do discurso do MESP a partir de simulacros que constroem acerca do PEPB, principalmente no que se refere à construção democrática dos saberes. A partir dessa reflexão, considera-se a existência de uma dicotomia, pois, de um lado, o jovem PEB busca fortalecer as bases democráticas do país, e, em contrapartida, o MESP tenta controlar o fazer educativo, contrapondose à reflexão crítica.

Palavras-chave: paulo freire. pensamento educacional progressista brasileiro. movimento escola sem partido.

\section{PAULO FREIRE AND BRAZILIAN PROGRESSIVE EDUCATIONAL} THOUGHT: attacks by School without Party

\begin{abstract}
The objective is to highlight the advances made by the Movement School without Party (MESP) to the democratic and autonomous principles of the Brazilian Progressive Educational Thought (PEPB) through offensives to the thought of Paulo Freire. Therefore, through a qualitative bibliographic research, expressive names in the Brazilian educational scenario stand out: Anísio Teixeira, Paulo Freire and Dermeval Saviani, highlighting Freire, as well as the challenges faced by them in the defense of democratic education. It also addresses the construction of the MESP's discourse from simulacra that build on the PEPB, especially with regard to the democratic construction of knowledge. Based on this reflection, the existence of a dichotomy is considered, since, on the one hand, the young PEB seeks to strengthen the democratic bases of the country, and, on the other hand, the MESP tries to control educational activities, in opposition to critical reflection.
\end{abstract}

Keywords: paulo freire. brazilian progressive educational thought. school without party movement.

\section{PAULO FREIRE Y EL PENSAMIENTO EDUCATIVO PROGRESISTA BRASILEÑO: ataques de la Escola sin Partido}

Resumen

El objetivo es resaltar los avances del Movimiento Escuela sin Partido (MESP) a los principios democráticos y autónomos del Pensamiento Educativo Progresista Brasileño (PEPB) a través de ofensivas al pensamiento 
de Paulo Freire. Por lo tanto, a través de una investigación bibliográfica cualitativa, se destacan nombres expresivos en el escenario educativo brasileño: Anísio Teixeira, Paulo Freire y Dermeval Saviani, destacando a Freire, así como los desafíos que enfrentan en la defensa de la educación democrática. También aborda la construcción del discurso del MESP a partir de simulacros que se construyen sobre el PEPB, especialmente en lo que se refiere a la construcción democrática del conocimiento. Con base en esta reflexión, se considera la existencia de una dicotomía, ya que, por un lado, el joven PEB busca fortalecer las bases democráticas del país, y, por otro lado, el MESP intenta controlar las actividades educativas, en oposición a la reflexión crítica. Palabras clave: paulo freire. pensamiento educativo progresivo brasileño. movimiento escuel sin partido.

\title{
CONSIDERAÇÕES INICIAIS
}

\begin{abstract}
Consequentemente, o que provoca o impulso investigativo é a necessidade de responder a alguma questão que nos interpela na realidade presente. [...] Trata-se, antes, da própria consciência da bistoricidade bumana, isto é, a percepção de que o presente se enraiza no passado e se projeta no futuro. Portanto, eu não posso compreender radicalmente o presente se não compreender as suas raízes, o que implica o estudo de sua gênese (SAVIANI, 2019, p. 566).
\end{abstract}

Nos últimos anos, no Brasil, a educação tornou-se o centro de debates político-ideológicos. Em grande parte, não com foco nas melhorias e avanços necessários, mas com atenção crítica e controladora às práticas educativas orientadas por um pensamento educacional notadamente brasileiro que se desenvolve sob bases democráticas, constituindo a estrutura da educação no Brasil.

A consolidação de uma educação democrática, pública, para todos, que proporcione ao estudante uma consciência crítica capaz de refletir acerca da sua função histórico-social como indivíduo em uma sociedade de classes foi o anseio de educadores nacionais que delinearam teorias fundamentais à proposta de educação pensada para o povo brasileiro. Nesse viés, Anísio Teixeira (Educação não é privilégio, 1999 [1957]), Paulo Freire (Pedagogia do Oprimido, 2013 [1968]), Dermeval Saviani (Escola e Democracia, 2018 [1983]), entre outros, tornam-se expoentes na construção de um pensamento educacional direcionado ao povo brasileiro, vislumbrando uma educação que possibilitasse a superação das desigualdades sociais, tornando o homem sujeito do seu próprio conhecimento no que diz respeito à reflexão e compreensão do mundo social.

Nessa perspectiva, o movimento conservador autodenominado Movimento Escola sem Partido (MESP) destaca-se, sobretudo a partir de 2014, pela construção do que aqui entendemos como um contradiscurso à coesão discursiva que, ao longo dos anos, consolidou as bases do que aqui chamamos de Pensamento Educacional Progressista Brasileiro (PEPB) ${ }^{1}$. Através de discursos amplamente divulgados na mídia, principalmente na internet, o MESP atua na tentativa de invalidar o pensamento educacional construído ao longo dos anos no Brasil, com propostas que tolhem,

\footnotetext{
${ }^{1}$ Estamos considerando que o Brasil cunhou, ao longo de sua história, ideias educacionais próprias e específicas que fundamentam hoje o ideal de educação pública de nosso país. Assim, neste artigo, Pensamento Educacional Progressista Brasileiro define um conjunto de visões que historicamente constituíram as bases teóricas que fundamentam uma vertente democrática do pensamento educacional do Brasil. Ainda que a necessidade de recorte tenha limitado nossas escolhas aos autores supracitados, reconhecemos que diversos outros autores poderiam compor a discussão. Nossas escolhas pautaram-se na contribuição abrangente e plural dos teóricos arrolados para a construção de um pensamento educacional que de fato sirva ao Brasil ao povo brasileiro, cidadãos desse Estado democrático de direito, tendo em vista ainda que seus pressupostos possibilitam uma busca constante pela superação das lacunas ainda existentes numa educação que se queira de fato para todos (indígenas, quilombolas, deficientes, LGBTQIA+ etc).
} 
sobretudo, a liberdade de ensinar e aprender, propondo regras e delimitando temas de discussão em sala de aula, na tentativa de restringir as reflexões possíveis através da educação. Esse ataque toma como bandeira, principalmente, a figura de Paulo Freire e os seus pressupostos para a educação brasileira

Diante da necessidade de compreender esse cenário, objetivamos, nesta pesquisa, discutir de que forma o discurso do MESP produz simulacros ${ }^{2}$ a partir de uma relação discursiva polêmica com o discurso do PEPB, destacando as importantes contribuições de Paulo Freire para a consolidação do PEPB. Adotamos, então, a perspectiva da Análise do Discurso de linha francesa, que considera, segundo Maingueneau (2008), o discurso como uma dispersão de textos circunscritos historicamente, tendo o interdiscurso primazia na relação discursiva e ressaltando o caráter dialógico dela.

Sob essa ótica, por entendermos que um discurso polêmico não dialoga com outro discurso (seu concorrente), mas com o simulacro que cria dele, adotamos um percurso metodológico bibliográfico que visa, inicialmente, evidenciar o que denominamos no referido trabalho como Pensamento Educacional Progressista Brasileiro, evidenciando os pressupostos de Paulo Freire, para, em seguida, delinearmos em que medida tal pensamento é retomado e refutado no discurso do MESP.

Podemos, pois, considerar que os primórdios da construção de um pensamento educacional brasileiro se dão desde a chegada dos portugueses no Brasil e, posteriormente, com a vinda dos jesuítas, em uma linha histórica horizontal. Contudo, tais práticas pedagógicas refletiam os ideais europeus vigentes na época, ainda que com uma tentativa de aproximação da realidade brasileira, através dos recursos pedagógicos utilizados na catequização e educação dos povos indígenas, como o teatro e o canto. Nesse viés, não em recusa à história da pedagogia que se desenvolveu do século XVI em diante, consideramos, na referida pesquisa, o desdobramento deste pensamento nacional em uma vertente mais progressista que se dá a partir do final da década de 1920, à luz dos estudos de três autores específicos; salientando, ainda, que as perspectivas teóricas por eles desenvolvidas foram concebidas em um determinado contexto histórico que implica em particularidades e visões específicas, ainda que, muitas vezes, sobre ideais em alguma medida equivalentes ou complementares.

Neste artigo, para evidenciar os ataques ao Pensamento Educacional Progressista Brasileiro produzidos pelo MESP, trataremos, num primeiro momento, da constituição de um pensamento educacional voltado à realidade brasileira a partir dos pressupostos de Anísio Teixeira (1999 [1957]), Paulo Freire (2014 [1967], 2016 [1980]) e Dermeval Saviani (2018 [1983], 2019 [2007]), de modo a evidenciar o cerne do que compõe as bases desse pensamento, sobretudo a partir das contribuições de Paulo Freire $(2014,2016)$. Logo após, discutiremos o discurso do MESP por meio de sua relação interdiscursiva polêmica estabelecida com o PEPB através, sobretudo, de simulacros. Por fim, evidenciaremos a tentativa de homogeneização da educação almejada pelo MESP através de discursos fundamentados em ideias não democráticas e a necessidade de fortalecermos os ideais democráticos e libertadores propostos por Paulo Freire.

\footnotetext{
${ }^{2}$ Considerando um espaço discursivo constituído por uma polêmica, compreendemos, na perspectiva teórica de Dominique Maingueneau (2008), que as unidades mínimas de significação, os semas de cada discurso, podem ser divididas em semas positivos (reivindicados) e semas negativos (rejeitados) frente a dado discurso concorrente. Isso faz com que um discurso "compreenda" o outro a partir dos semas negativos, ou seja, dos semas que ele rejeita. Dessa forma, um discurso não dialoga com outro discurso, mas com o simulacro que produz dele, evidenciando e até distorcendo os semas que rejeita e dialogando, de fato, com uma espécie de caricatura ou imagem que constrói desse discurso outro.
} 


\section{ANÍSIO TEIXEIRA E A ESCOLA PROCLAMADA PARA TODOS}

No cenário educacional brasileiro do século XX, Anísio Teixeira tem projeção pautada na defesa da educação através da democratização do acesso à educação como um direito de todos. Seus pressupostos mobilizaram grande atenção à organização das instituições de ensino, bem como ao desenvolvimento da ciência através de pesquisas. É um dos grandes nomes que constituem as bases do Pensamento Educacional Progressista Brasileiro.

Para Anísio Teixeira (1999, p.83), “[...] obrigatória, gratuita e universal, a educação só poderia ser ministrada pelo Estado". Não era possível que iniciativas privadas a oferecessem nesse formato, tendo em vista que iriam oferecer educação aos que já tinham posses, agindo mais "para perpetuar as desigualdades sociais que para removê-las". Logo, Teixeira (1999) ensina que a educação deveria ser a base comum de oportunidades, de onde todos partiriam, não uma instância para a manutenção de privilégios.

Frente aos ideais de Anísio de estabelecer um pensamento que fortalecesse a educação brasileira, aliando teoria e prática, pautado na autonomia, no pluralismo de ideias e na democracia, mostrava-se muito provável que as forças controladoras que se viam como detentoras do conhecimento não aceitariam e lutariam contra esses avanços. Ciente disso, Anísio Teixeira (1999) já afirmava que, ao menor sinal de ameaça à hegemonia das elites no país, projetos educacionais que alcancem as camadas mais baixas da sociedade e que ofereçam a elas a possibilidade de reflexão crítica seriam fortemente combatidos. Nesse período, ele já representava uma ameaça à rigidez do sistema político-educacional brasileiro oligárquico. Logo, mesmo que contrário à militância política, ao se atentar aos interesses populares, seria combatido. E assim o foi.

Desde os anos de 1920, Anísio Teixeira vinha delineando ideias que contribuíram com a construção das bases do PEPB. Após as investidas contra a democracia em 1937, com o Estado Novo, Anísio busca reestabelecer as bases democráticas educacionais e afirma que "[...] se vale alguma coisa a análise que fizemos, temos de descobrir, baseados nela, os meios de corrigir e reorientar a situação, no sentido de revigorar certas forças e superar ou contrabalançar outras" (TEIXEIRA, 1999, p. 98). Afinal, a educação pública poderia oferecer, em sua visão, uma oportunidade de igualdade entre as classes, e, ainda que as diferenças viessem posteriormente, seria a escola pública um lugar comum das classes.

Ainda que não alinhado oficialmente com partidos políticos ou em defesa de um ideal de direita ou de esquerda, o pensamento de Anísio Teixeira sofreu fortes ataques em períodos autoritários como o do Estado Novo e o do golpe militar de 1964, o que gerou graves consequências, sobretudo, por defender uma educação democrática que não servisse aos interesses de uma elite dominante e que se transformasse junto à população, de todas as classes, inclusive com uma gestão aberta e também democrática.

\section{PAULO FREIRE E A EDUCAÇÃO CRÍTICA E REFLEXIVA}

Os ideais democráticos e de rompimento dos domínios coloniais que buscavam se perpetuar na educação brasileira estenderam-se a outros pensamentos educacionais de viés crítico, democrático e participativo e contribuíram para a formação do que nomeamos PEPB.

Nesse cenário, as inquietações acerca da falta de espírito democrático na sociedade brasileira também incomodavam ao educador pernambucano Paulo Freire. Para Freire (2014, posição 1263), a importância do estado democrático não se dava somente frente a um período de governo colonial ao qual erámos submetidos, "mas também, e, sobretudo, quando não tínhamos ainda condições capazes de oferecer ao 'povo' inexperimentado circunstâncias ou clima para as 
primeiras experiências verdadeiramente democráticas". Reafirmando, assim, a importância de fortalecermos a democracia a fim de superarmos as heranças colonizadoras que insistiam em uma educação elitista que estaria longe de ser libertadora.

Nesse sentido, os ideais pedagógicos de Freire representam, então, a continuidade da defesa de uma educação democrática e universal que vinha consolidando as bases do PEPB, mas agora acentuando a educação como ato político que deveria, para além de métodos e técnicas educacionais, possibilitar a inserção do sujeito na educação de tal modo que ele se tornaria capaz de refletir criticamente sobre sua realidade social.

A reflexão crítica do educando sobre sua própria realidade permite que ele busque a transformação dessa realidade. Alcançando, assim, a conscientização que permite que ele compreenda a necessidade de romper com as classes dominantes e com a rígida estrutura social que o furta a educação libertadora. Sendo sujeitos conscientes, "[...] eles descobrem que o mundo é deles e não de uma classe dominante" (FREIRE, 2020. p. 137).

O Pensamento Educacional Progressista Brasileiro vem se desenvolvendo, então, a partir de ideais emancipatórios e democráticos que promovam a liberdade dos sujeitos de modo a provocar uma reflexão crítica acerca da sociedade. Como afirmam Autores (2021, p. 6), “[...] para alguns, alcançar tal intento é afrontoso e, para a classe dominante, subversivo; afinal, a ordem já havia sido por ela determinada e as classes irrevogavelmente definidas".

Desde a década de 1960, Paulo Freire já vinha desenvolvendo ações de alfabetização de jovens e adultos e, bem entusiasmado com o progresso dos seus alunos, compartilha com amigos que, através de alguns contatos, viabilizam um projeto de alfabetização. A cidade escolhida para iniciar a aplicação do método Paulo Freire de alfabetização foi a cidade de Angicos. Vários estudantes vieram da capital do estado para colaborar no desenvolvimento das ações. O contato com a população era estreito, a fim de planejarem as ações e elaborarem as aulas em consonância com a realidade dos alunos. As aulas iniciavam com a valorização do conhecimento de cada um que ali estava, fosse o professor, o aluno carpinteiro, a aluna cozinheira, a aluna lavradora, o aluno pedreiro... (HADDAD, 2019). O reconhecimento do aluno como parte integrante do processo de alfabetização e a inserção dele como sujeito agente da sua educação eram fundamentais para Paulo Freire e, de fato, proporcionaram educação linguística e política eficiente e veloz. Para Freire (2020, p. 139), sobre o processo de alfabetização dos alunos, “[...] era como se eles estivessem emergindo de seu mundo para entendê-lo pela primeira vez", afinal, eles se tornavam capazes não simplesmente pela habilidade de leitura e escrita, mas por saberem da sua condição de educandos e tomarem consciência disso.

Considerando que, nesse cenário, já se desenhavam as bases de um pensamento educacional próprio do Brasil, os aspectos intrínsecos a essa sociedade foram norteadores desse processo. Se antes havia a defesa da democracia e da garantia de uma educação capaz de promover o que Anísio Teixeira já propagava em suas ideias; agora, sob a ótica de Paulo Freire, isso precisaria perpassar pelo aluno para ultrapassar os muros da escola. Considera-se, então, a importância fundamental da participação livre e crítica do alunado no ato educativo, respeitando-o e valorizando-o a partir de seu próprio mundo, num claro incentivo ao diálogo democrático.

A promoção do diálogo democrático a partir de uma reflexão crítica é um dos cernes dos pressupostos de Freire, tão caros à consolidação das bases do Pensamento Educacional Progressista Brasileiro. O PEPB fundamenta uma educação que busca a constante transformação e reflexão crítica, defendendo, também, a necessidade de adaptação da educação, seja nos currículos ou nos métodos, de modo a alcançar o que deve ser seu objetivo: "[...] permitir ao homem tornarse sujeito, construir-se como pessoa, transformar o mundo, firmar relações de reciprocidade com os outros homens, formar sua própria cultura e fazer história...” (FREIRE, 2016, p. 74). 
É possível, dessa forma, inferir que, nos momentos em que houve um movimento de ação em direção à democracia, houve também um movimento de reação por parte das elites dominantes para reprimir. Conforme os pressupostos de Anísio Teixeira - que afirmam ser a escola pública a grande máquina capaz de preparar a democracia - e conforme os ideais de Paulo Freire - que apontam o pensamento democrático como fruto de uma educação que dialoga, discute, debate, valoriza e não uma que impõe - só se alcançaria a educação democrática se se fizesse, de fato, uma opção por ela. Segundo Freire (2016), era preciso assumir a liberdade como ponto de partida da educação, como era feito nos círculos de cultura, porque a aprendizagem eficiente só se dá em relações dialógicas e democráticas entre todos os envolvidos.

Nesse sentido, a alfabetização de mais de 400 iletrados em Angicos (RN) representa uma consolidação das bases democráticas da educação e o fortalecimento das relações dialógicas, apontando, assim, para uma possibilidade cada vez mais real de rompimento do status quo. Talvez por isso, na noite de encerramento das aulas em Angicos, o general Castelo Branco diz a Paulo Freire que havia sido alertado "sobre o seu caráter subversivo" e que, após aquele momento, então, ele se convencera disso "por sua defesa de uma "pedagogia sem hierarquia"' (discurso retomado hoje por adeptos do Movimento Escola sem Partido). Um ano depois, Paulo Freire é preso (HADDAD, 2019, p. 859).

A prisão de Freire demonstra claramente o intuito do golpe militar de 1964: desarticular as ações emancipatórias e populares do país, num dos momentos de maior possibilidade de ascensão da classe popular. Embora diversos políticos tenham voltado seus olhos para a possibilidade de aumentar o número de eleitores através da alfabetização em massa, não seria através do pensamento educacional desenvolvido por Freire que alcançariam tal objetivo. Conforme a pedagogia da liberdade de Freire, "[...] formar para a democracia não pode significar somente transformar o analfabeto em eleitor, submeter-se às alternativas de um esquema de poder já existente" (FREIRE, 2016, p. 46). Essa prática pedagógica deveria "[...] ao mesmo tempo preparar para um juízo crítico das alternativas propostas pelas elites e dar a possibilidade de escolher o próprio caminho" (FREIRE, 2016, p. 47).

Em meio às acusações de subversão e de querer implantar o comunismo no país, Paulo Freire foi levado por dois agentes militares para prestar esclarecimentos e não voltou mais para casa, ficando preso por algumas semanas. Freire prestou depoimentos detalhados sobre sua atuação como educador, além dos já prestados na universidade em decorrência do AI I. "Somados os dois períodos de encarceramento, em Recife e em Olinda, Paulo ficou preso por mais de setenta dias" (HADDAD, 2019, p. 218). Após ser solto, diante da eminente possibilidade de ser novamente preso e preocupado com sua esposa e seus cinco filhos, Freire dá maior atenção aos conselhos dos amigos sobre o exílio. Parte, assim, em outubro de 1964, junto ao embaixador da Bolívia para aquele país.

Vários trabalhos importantes de Freire foram produzidos após sua saída do Brasil, inclusive a publicação do seu mais famoso livro, Pedagogia do Oprimido, obra que alçou altos voos e ratificou as práticas pedagógicas que vinham fundando as bases do Pensamento Educacional Progressista Brasileiro: o homem e a sociedade. O homem deveria ser esclarecido, dotado de consciência crítica e, por meio de uma educação democrática, refletir criticamente sobre si para que fosse possível romper com a realidade de uma estrutura dominante. Os discursos enunciados por Anísio Teixeira e Paulo Freire proporcionaram, assim, a criação de uma base consistente do que se pensava para a educação brasileira; representavam o rompimento com um ideal colonialista que não considerava as necessidades próprias do povo brasileiro e que, por isso mesmo, ameaçava o status quo.

Vale salientar que as bases do Pensamento Educacional Progressista Brasileiro não foram traçadas em unicidade por ideais pedagógicos consonantes. Todavia, com suas incongruências, convergiam 


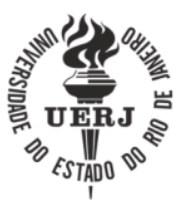

DOI: $10.12957 /$ teias.2021.62067

na defesa de uma escola pública, democrática e para todos. É preciso, portanto, considerar o período histórico no qual as ideias se desenvolveram e as influências teóricas que receberam ao longo desse período.

\section{DERMEVAL SAVIANI E A EDUCAÇÃO CRÍTICA E DEMOCRÁTICA}

Enxergando na educação o caminho que possibilita a transformação social, Dermeval Saviani, assim como Anísio Teixeira e Paulo Freire, pauta seus ideais pedagógicos na democracia. Ainda que partindo de bases filosóficas diferentes, os pressupostos de todos eles reconhecem as relações de poder que são estabelecidas na realidade social dos cidadãos. Em específico, Saviani compõe o que chamamos de PEPB sobretudo pela capacidade agregadora de analisar e interpretar a trajetória educacional de nosso país para propor uma perspectiva histórico-crítica que busca superar o pretenso poder hegemônico da burguesia numa visão dialética. É nesse sentido que refletiremos aqui sobre a contribuição dada por Saviani à consolidação do PEPB; haja vista que, para além das críticas tecidas pelo autor a alguns movimentos anteriores, como a Escola Nova, ele evidencia a necessidade de apropriação do conhecimento historicamente elaborado através da educação, o que promove a criticidade.

Em seu livro Escola e Democracia, Saviani (2018) aponta diferentes teorias pedagógicas e de que modo elas enxergavam a marginalização dos indivíduos na sociedade. Assim, o autor divide essas teorias em dois grupos: teorias não críticas e teorias crítico-reprodutivistas. As primeiras entendem que a educação não possui relação direta com a sociedade, afinal, a marginalização é considerada acidental e afeta individualmente os membros de uma sociedade. A educação surge, então, como uma possibilidade de superar essa marginalidade e de prover equalização social, ou seja, como uma oportunidade do homem se adequar ao que lhe é proposto pela sociedade em dada circunstância. As segundas teorias, as crítico-reprodutivistas, compreendem que a marginalização é inerente à própria estrutura social, que é dividida em classes, em que a mais forte domina as mais fracas. A educação, assim, seria um fator de marginalização, pois tem se tornado cada vez mais opressiva e discriminatória. São reprodutivistas essas teorias porque objetivam apenas evidenciar como as escolas já são e os problemas que possuem, sem propor alternativas para resolvê-los. Segundo Saviani (2018, p. 898), no âmbito pedagógico do Brasil, temos, então, de um lado, teorias não críticas que tentam superar a marginalidade através da escola sem nunca conseguir; e, de outro lado, as crítico-reprodutivistas, que se limitam a explicar o "suposto fracasso da escola".

Já dentre as teorias críticas que aponta Saviani (2018), estão as Teorias CríticoReprodutivistas e a Pedagogia Histórico-Crítica, a última correspondendo a uma proposta pedagógica elaborada por Saviani com o objetivo de se ter um estudo aplicável à realidade brasileira. A Pedagogia Histórico-Crítica (PHC), assim nomeada a partir de 1984, proposta por Dermeval Saviani (2018), que se sustenta no conceito de uma sociedade de classes, com conteúdos educacionais críticos oriundos da prática social vivida no contexto escolar. Tal proposta, portanto, entrelaça-se às bases teóricas do Pensamento Educacional Progressista Brasileiro numa concepção de fato dialética, partindo do diálogo com os contrários para que se atinja a emancipação necessária para produzir consciência.

Convém destacar que os pressupostos de Saviani foram desenvolvidos em meados da década de 1980 e são constantemente debatidos e aprofundados pelo próprio autor até os dias atuais, a fim de refletir acerca da relação política-educação. No prefácio da $5^{a}$ edição de História das ideias pedagógicas no Brasil, Dermeval Saviani aponta que a nova edição do livro "[...] vem à luz num momento difícil da vida nacional em que aumentam os indícios de que a civilização vem 
crescentemente perdendo terreno para a barbárie". Para Saviani (2019, p. 22), vivemos um momento em que a educação tende "a ser reduzida a um instrumento de doutrinação a serviço de uma ideologia que subordina a razão e a ciência a crenças e mistificações", a educação, sobretudo a escola pública, que vinha transformando "súditos em cidadãos" tem se deparado, então, com esse desafio.

Nessa perspectiva, é possível nos questionarmos de que modo o Movimento Escola sem Partido ataca os princípios democráticos e autônomos do Pensamento Educacional Progressista Brasileiro através das ofensivas ao pensamento de Paulo Freire.

\section{UMA FACE DO MOVIMENTO ESCOLA SEM PARTIDO}

Historicamente, a classe dominante lança mão de estratégias que impossibilitam a transformação da sociedade através da educação, seja por meio da perpetuação de práticas pedagógicas colonizadoras, seja por meio de entraves impostos às classes mais baixas no que tange ao acesso à educação ou frente à mobilização de pessoas dispostas a manter a hegemonia das classes dominantes.

Nos últimos anos, discursos de ódio têm alcançado maior projeção no Brasil, seja para atacar movimentos sociais, seja professores, ideais progressistas ou mesmo o bem público. Casimiro (2018, p. 41) identifica esse processo como uma “[...] reorganização das classes dominantes que lança suas raízes em meados dos anos de 1980 e que tem como uma de suas manifestações, entre várias outras, o surgimento de um novo modus operandi de ação políticoideológica". A educação, em específico, sofre tais ataques sobretudo pelo fortalecimento que o cenário vem buscando através da consolidação do PEPB e ampliação do que se desenhou como uma educação para todos, na defesa de ideais democráticos. A relação interdiscursiva travada no campo escolar dá-se em especial sob a forma de simulacros e distorções produzidos por grupos específicos que, a partir das suas próprias "leituras" e traduções do discurso outro, combatem-no.

Nesse cenário político, tem-se fortes ataques à democracia no âmbito da educação libertadora e crítica, na tentativa de confrontar políticas de combate à desigualdade social, que visam a inclusão e a garantia de direitos de minorias na perspectiva do que vem sendo construído pelo PEPB. O autodenominado Movimento Escola sem Partido projeta-se, então, nessa conjuntura, com um discurso travado contra a suposta doutrinação praticada dentro das salas de aulas por professores que constituem um "exército de militantes da esquerda", que se vale da liberdade de cátedra e da "cortina de segredo das salas de aula" para impor algo indesejado aos alunos, constrangendo-os com uma visão de mundo própria desses professores (NAGIB, s.d).

É preciso considerar que historicamente, no Brasil, o acesso à educação pública se deu na tentativa de aprimorar a força de trabalho por meio de um ensino tecnicista que privava as camadas mais baixas da população de um ensino amplo e rico culturalmente. Como informa Mészáros (2005, p. 468-469), o propósito da educação institucionalizada nos últimos 150 anos foi o "de não só fornecer os conhecimentos e o pessoal necessário à máquina produtiva em expansão do sistema do capital, como também gerar e transmitir um quadro de valores que legitima[sse] os interesses dominantes", apesar de sucessivos e ininterruptos contramovimentos do PEPB a partir da década de 1930. Ainda que com suas especificidades, e em referência à regionalização das escolas e autonomia dos municípios, Anísio Teixeira (1999, p. 65) afirma que "a escola de formação do brasileiro não pode ser uma escola imposta pelo centro, mas produto das condições locais e regionais, planejada, feita e realizada sob medida para a cultura da região”. Aí já existia o gérmen 
que se desenvolveria, em outros contextos históricos, e floresceria de modo a contribuir com a consolidação do Pensamento Educacional Progressista Brasileiro.

Assim, é possível deduzir que os discursos defendidos pelo MESP se contrapõem à luta em prol da construção de uma educação pública e de qualidade travada desde Anísio Teixeira, ampliada por Freire com seus ideais de autonomia e criticidade ou como o faz Saviani através da defesa de um processo histórico-crítico. O MESP tenta, a todo momento e de diversas formas, confrontar essa luta e, como ocorreu desde outros contextos, frear os avanços desses ideais e manter privilégios, seja por leituras fantasiosas das bases do Pensamento Educacional Progressista Brasileiro, seja por difusão dos discursos de ódios em redes sociais. Conforme afirma Maingueneau (2008, p. 108), essa relação polêmica entre discursos "[...] aparece exatamente como uma espécie de homeopatia pervertida: ela introduz o Outro em seu recinto para melhor afastar sua ameaça, mas esse Outro só entra anulado enquanto tal, simulacro". Na tentativa de propagar uma leitura do outro - do discurso do PEPB - o MESP se liga, então, ao que, para ele, é negativo, ao que lhe parece ameaçador. Vê-se por exemplo que o ideal de liberdade de Paulo Freire é traduzido pelo MESP como "falta de limites ou ausência de hierarquia entre professores e alunos". Do mesmo modo, o desenvolvimento da consciência crítica, ao passar pela grelha semântica do MESP, torna-se "doutrinação esquerdista".

Embora o MESP seja relativamente recente, há tempos a educação está no centro da disputa pela hegemonia dos que detém o poder, considerando-se os seus aspectos políticos sobretudo. Desde meados de 1984, através do Fórum da Liberdade, como aponta Casimiro (2018, p. 42), diversas entidades liberais do mundo expandiam no Brasil pensamentos conservadores, fazendo desse Fórum uma grande "vitrine de apresentação pública de diversos aparelhos ideológicos". Vários grupos econômicos industriais se mobilizam na busca de maior organicidade e formas de atuarem na sociedade brasileira em prol de seus interesses de acumulação de capital; a educação se torna, então, um mecanismo importante nesse processo. Certamente por isso, em 2006, o XIX Fórum da Liberdade faz o lançamento do Instituto Millenium, que possui estreita relação com o MESP 3 . Segundo Casimiro (2018, p. 45), sobre esses grupos, “[...] observa-se a paulatina substituição de uma postura mais contida e técnica por um discurso bem mais agressivo, com uma forte pauta moralista".

O Movimento Escola sem Partido foi criado em 2004 pelo advogado Miguel Nagib, supostamente após um descontentamento do advogado com afirmações feitas pelo professor de sua filha, que teria comparado Che Guevara a São Francisco de Assis ao utilizá-los como exemplos de pessoas que renunciaram a suas vidas por ideais nos quais acreditavam. Che Guevara em prol de ideais políticos e São Francisco de Assis de ideais religiosos. A partir desse momento, Nagib articula um grupo, inspirado em ações que ocorriam nos Estados Unidos contra a doutrinação em escolas, sobretudo no que se refere ao tratamento do racismo que, segundo o grupo, era abordado de forma tendenciosa pela escola. ${ }^{4}$ Vale destacar, ainda, que, segundo Linares e Bezerra (2019, p. 130), o MESP era "[...] um braço do portal Mídia Sem Máscara, criado em 2002 pelo astrólogo Olavo de Carvalho", não sendo, então, motivado apenas pelo que alega o seu fundador, e tendo

\footnotetext{
3 Segundo Severo (2019), Miguel Nagib, fundador do MESP, teve vínculos como articulador do Instituto Millenium, organização de caráter conservador, formada por empresários, jornalistas e profissionais liberais. Nagib foi autor de artigos e doador de tal Instituto.

${ }^{4}$ Para detalhes sobre o grupo norte-americano, ler Breve análise sobre as redes do Escola sem Partido, de Betty R. Solano Espinosa e Felipe B. Campanuci Queiroz, no livro Escola "sem” partido - esfinge que ameaça a educação e a sociedade brasileira.
} 


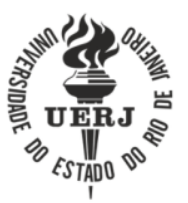

DOI: $10.12957 /$ teias.2021.62067

também ligações com o Instituto Millenium, organização vinculada às ações promovidas no Fórum da Liberdade.

O discurso autoritário, de ódio e de censura que outrora circulava em nossa sociedade vem à tona na atualidade e não disfarçado ou tentando assumir novos contrastes. Ao contrário, valemse de uma agenda contra a escola pública, laica e que promova o debate social a partir da realidade dos próprios alunos. Ou seja, discursam contra os ideais amplamente defendidos sobretudo por Paulo Freire na construção do Pensamento Educacional Progressista Brasileiro.

Em outubro de 1964, após ter partido para o exílio, Paulo Freire, inclusive, foi apontado pelo tenente-coronel Hélio Ibiapina Lima como “[...] um dos maiores responsáveis pela subversão imediata dos menos favorecidos", conforme afirma Haddad (2019, p. 142), numa manobra interdiscursiva que lê liberdade e consciência como subversão. Podemos visualizar, então, a contínua repressão à "subversão" dos menos favorecidos - ideia contida nas bases dos PEPB através de uma tentativa contínua de combate às abordagens capazes de possibilitar a reflexão e conscientização da população. Nota-se, portanto, o combate a ideais democráticos e, sobretudo, críticos que emergem do proletariado.

Nessa perspectiva, em um movimento interdiscursivo que resgata o discurso do outro para distorcê-lo, os ideais propagados pelo Movimento Escola sem Partido, em consonância com as práticas de governos autoritários com ideologias conservadoras bem definidas, são pautados no combate "à doutrinação" o que, segundo eles, ocorre nas escolas. Com isso, esperam uma educação "sem viés ideológico" e que não seja guiada por pressupostos que fundamentam o PEPB, como o ideal de liberdade, igualdade e consciência crítica.

É perceptível, então, que o combate é a todo e qualquer ideal que promova, democraticamente, a reflexão e a criticidade do homem acerca da sociedade, evidenciando, assim, os simulacros produzidos pelo MESP acerca do PEPB, pois, para manter a hegemonia das classes dominantes e minar ideais revolucionários que queiram romper com tal dominação, o MESP combate não o discurso do PEPB, mas o simulacro que constrói dele.

Almeida (2018, p. 31) aponta que, em momentos de fragilidade democrática, o que importa é a "[...] preservação das formas sociais, sendo todo o resto formado por questões circunstanciais que refletem o estágio das forças em conflito em cada tempo histórico". Nesse sentido, ele afirma que "democracia e cidadania são elementos importantes na medida em que denotam a estabilidade do sistema e a capacidade do Estado e das demais instituições a ele relacionadas de manter os conflitos e antagonismos que são inerentes à sociabilidade capitalista sob controle". A democracia expressa na sociedade capitalista reforça a ideia de coesão social, o que é mais ameaçador, portanto, é uma educação que, para além de ser democrática, possibilite ao sujeito alcançar, por meio da consciência crítica, a compreensão da sociedade de modo a buscar sua emancipação e promover uma transformação social. E é através dessa conscientização crítica transformadora que a opressão da classe dominante sobre as classes dominadas frustra-se. Por isso, movimentos conservadores como o MESP articulam-se constantemente na tentativa de manter as relações de forças dominantes.

Os discursos veiculados pelo MESP levam-nos a crer que existe a possibilidade de tal movimento tolher ou reduzir a criticidade do aluno, diminuindo o seu potencial reflexivo e, por consequência, sua capacidade de emancipação social; tendo em vista que a leitura de mundo do discente tenderá a ser, sob o modelo educacional por eles defendido, reprodutivista, limitada, pouco sóbria e alienada, sucumbindo, assim, o que se busca, conforme as bases do PEPB, para a escola brasileira. Mostra-se uma clara ofensiva aos ideais amplamente difundidos por Paulo Freire (2011, posição 1268) da educação como "uma forma de intervenção no mundo", não sendo jamais neutra ou indiferente. 
Ao focar no slogan sem partido, o movimento tenta ainda apontar um caminho contrário ao que, hipoteticamente, estaria sendo praticado nas salas de aula - uma doutrinação partidária de esquerda - criando, assim, simulacros, distorções acerca do que de fato constitui o PEPB. Tal posição é semelhante à afirmação de Adorno e Horkheimer $(1985$, p. 57) ao tratarem da indústria cultural e da mistificação das massas, quando mencionam que produtos apresentados como diferenciados acabam por ser a mesma coisa, apontando que "[...] as vantagens e desvantagens que os conhecedores discutem servem apenas para perpetuar a ilusão da concorrência e da possibilidade de escolha". Ou seja, o MESP, a partir do simulacro por eles criados de que há, no Brasil, uma escola partidária e doutrinadora - consequência do PEPB - tenta apresentar um contradiscurso, um "produto diferenciado"; contudo, o foco não é uma escola sem partido, mas com um partido específico - conservador - que não discuta as possibilidades de emancipação e de escolha dos sujeitos.

É possível compreender, então, que o MESP produz tais simulacros e os reforça através dos discursos amplamente divulgados, especialmente na mídia, que dizem tentar combater uma doutrinação, mas que fogem de ideais críticos e democráticos. O movimento, inclusive, não apresenta possiblidades de escolha aos alunos; ao contrário, suas propostas privam os alunos de ampliarem o repertório cognitivo-cultural e de apresentarem, em sala de aula, anseios e dificuldades da vida cotidiana, já que ao professor não é permitida a discussão de temas considerados "sensíveis". Isto é, há um claro intuito de controlar e homogeneizar uma sociedade heterogênea e de silenciar classes que outrora aprenderam a falar.

\section{PENSAMENTO EDUCACIONAL PROGRESSISTA BRASILEIRO: POR UMA EMANCIPAÇÃO CRÍTICA DOS SUJEITTOS}

Neste estudo, podemos considerar que a ação crítica do homem sobre sua própria existência possibilitaria a transformação dela, o que abala a estrutura tão bem definida das classes dominantes. Por tal motivo, ao longo da construção do Pensamento Educacional Progressista Brasileiro, pautado, sobretudo, em ideais democráticos que possibilitariam a consciência crítica do homem frente à sociedade na qual estaria inserido historicamente, por exemplo, é que forças conservadoras detentoras do poder, que almejavam a manutenção do status quo, atacavam veemente o desenvolvimento de ações educacionais progressistas. É notório que em meio à ascensão de uma educação para todos, há um combate para frear conquistas democráticas.

Os pressupostos de Paulo Freire (2011), por exemplo - tão caros à consolidação das bases do PEPB - evidenciam a necessidade de uma "prática educativo-crítica ou progressista", de modo a consolidar definitivamente a ideia de "que ensinar não é transferir conhecimento, mas criar as possibilidades para a sua produção ou a sua construção". Essa visão que relaciona currículo e experiência social dos alunos vai de encontro ao discurso em defesa da transmissão de conteúdo, discursos de conservadores, "reacionariamente pragmático[s]" que afirmam: "[...] a escola não é partido. Ela tem que ensinar os conteúdos, transferi-los aos alunos" (FREIRE, 2011, posição 267$368)$.

Nesse viés, o MESP cresce produzindo distorções a partir da relação interdiscursiva polêmica estabelecida com o PEPB, que acaba por evidenciar uma tentativa de combate aos ideais democráticos sob o simulacro de serem eles uma construção de doutrinação e de aprisionamento da população. Mas qual seria o aprisionamento possível a uma mente consciente criticamente? Se, segundo os pressupostos de Paulo Freire, a consciência crítica promove a reação das massas é porque existe, então, uma situação de opressão. O MESP reproduz, nessa perspectiva, ações 
semelhantes às realizadas anteriormente em governos autoritários, desconsiderando o homem como sujeito, agente social, vendo-o como objeto paciente de ações que interessam a dada minoria, tolhendo-lhe possibilidades emancipatórias e de superação de desigualdades.

Em confronto a essa realidade é que a pesquisa em educação precisa, portanto, problematizar a atual realidade educacional a fim de confrontar a homogeneidade dos saberes científicos para, assim, produzir resultados que ofereçam ganhos sociais e não apenas ganhos na esfera acadêmica. Não devemos refletir sobre o que foi problematizado apenas para comunicar aos nossos pares, mas devemos, junto aos nossos pares, ampliar a discussão e fomentar a participação popular numa relação dialética capaz de produzir conscientização através da educação, capaz de esperançar, em uma busca constante por reencantar o mundo.

\section{REFERÊNCIAS}

ALMEIDA, Silvio Luiz de. Neoconservadorismo e liberalismo. In: GALLEGO, Esther (org.). O ódio como política: a reinvenção das direitas no Brasil. 1. ed. São Paulo: Boitempo, 2018.

CASIMIRO, Flávio Henrique Calheiros. As classes dominantes e a nova direita no Brasil contemporâneo. In: GALLEGO, Esther (org.). O ódio como política: a reinvenção das direitas no Brasil. 1. ed. São Paulo: Boitempo, 2018.

FREIRE, Paulo. Conscientização. Trad. Tiago José Risi Leme. São Paulo: Cortez, 2016.

FREIRE, Paulo. Educação como prática de liberdade. E-book Kindle. São Paulo: Paz e Terra, 2014.

FREIRE, Paulo. Pedagogia da autonomia: saberes necessários à prática educativa. E-book Kindle. São Paulo, Paz e Terra, 2011.

FREIRE, Paulo. Direitos humanos e educação libertadora: gestão democrática da educação pública na cidade de São Paulo. Rio de Janeiro/São Paulo, Paz e Terra, 2020.

HADDAD, Sérgio. O educador - um perfil de Paulo Freire. E-book Kindle. São Paulo: Todavia, 2019.

HORKHEIMER, Max; ADORNO, Theodor W. Dialética do esclarecimento. Rio de Janeiro: Jorge Zahar Ed., 1985.

LINARES, Alexandre. BEZERRA, José Eudes Baima. Obscurantismo contra a liberdade de ensinar. In: CÁSSIO, Fernando (org.). Educação contra a barbárie: por escolas democráticas e pela liberdade de ensinar. 1. ed. São Paulo: Boitempo, 2019.

MAINGUENEAU, Dominique. Gênese do discurso. São Paulo: Parábola Editorial, 2008.

SAVIANI, Dermeval. Escola e Democracia. E-book Kindle. 43․ ed. Campinas: Autores Associados, 2018.

SAVIANI, Dermeval. Histórias das ideias pedagógicas no Brasil. E-book Kindle. 5a.ed. Campinas: Autores Associados, 2019.

TEIXEIRA, Anísio. Educação não é privilégio. 6.ed. Rio de Janeiro: Editora UFRJ, 1999. 


\section{Informações do(a)(s) autor(a)(es)}

Isabela Maria Oliveira Catrinck

Universidade Estadual de Montes Claros - Unimontes

E-mail: isabelac.educacao@gmail.com

ORCID: https://orcid.org/0000-0001-6843-8592

Link Lattes: http://lattes.cnpq.br/7538800784065335

Maria Clara Maciel de Araújo Ribeiro

Universidade Estadual de Montes Claros - Unimontes

E-mail:mclaramaciel@hotmail.com

ORCID: https://orcid.org/0000-0001-9205-5858

Link Lattes: http://lattes.cnpq.br/3608817167733880 